CLINICAL STUDY

\title{
Treated hypothyroidism, cognitive function, and depressed mood in old age: the Rancho Bernardo Study
}

\author{
Caroline K Kramer ${ }^{1,2}$, Denise von Mühlen ${ }^{1}$, Donna Kritz-Silverstein ${ }^{1}$ and Elizabeth Barrett-Connor ${ }^{1}$ \\ ${ }^{1}$ Division of Epidemiology, Department of Family and Preventive Medicine, School of Medicine, University of California, San Diego, La Jolla, California \\ 92093-0607, USA and ${ }^{2}$ Endocrine Division, Hospital de Clínicas de Porto Alegre/Programa de Pós -graduação em Ciencias Médicas: Endocrinologia, \\ Porto Alegre, RS, 90035-003, Brazil \\ (Correspondence should be addressed to E Barrett-Connor; Email: ebarrettconnor@ucsd.edu)
}

\begin{abstract}
Objective: Overt hypothyroidism is associated with cognitive impairment, which can be reversed if treated early and appropriately. We compared cognitive function (CF) of euthyroid older adults with those who had long-term treated hypothyroidism.

Methods: Between 1999 and 2003, the CF of 885 euthyroid and 149 hypothyroid-treated older adults (primary hypothyroidism after surgery or autoimmune thyroid disease) was assessed using three standardized CF tests: the modified mini-mental state examination, Trails B, and verbal fluency. Depressed mood was assessed using the Beck Depression Inventory (BDI). Only participants with thyroid stimulating hormone (TSH) in the normal range were included.

Results: The treated hypothyroid group had been treated with L-thyroxine for an average of 20 years. Those with treated hypothyroidism were older than the euthyroid group $(76.1 \pm 9.6$ vs $73.6 \pm 10.2$ years, $P=0.005)$ and were much more often women $(81.6$ vs $54.8 \%, P<0.001)$. TSH levels were similar between groups (median interquartile range $=1.57(1.19)$ vs $1.54(1.59) \mathrm{mIU} / \mathrm{l}, P=0.81$ ). Compared to euthyroid, the treated hypothyroidism group had more frequent antidepressant medication use $(19.5$ vs $8.5 \%, P<0.001)$ but similar BDI scores. Performance on the three CF tests did not differ by thyroid hormone treatment. Results were not changed after adjustment for age, sex, antidepressant medication use, exercise, and total cholesterol.

Conclusion: Long-term treated hypothyroidism is not associated with impaired CF or depressed mood in old age. The lack of association with CF is reassuring with regard to long-term use of thyroid hormone therapy.
\end{abstract}

European Journal of Endocrinology 161 917-921

\section{Introduction}

Thyroid hormones play an important role in human brain function $(1,2)$. Overt hypothyroidism is associated with impairment of cognitive function $(\mathrm{CF})$ in several cognitive domains including attention and concentration, memory, perceptual and visuospatial function, language, and executive function $(1,3)$. The effect of elevated thyroid stimulating hormone (TSH) and subclinical hypothyroidism treatment on $\mathrm{CF}$ and mood is less clear.

Previous studies of the association of elevated TSH (mostly subclinical hypothyroidism) with $\mathrm{CF}$ and mood are sparse and yield inconsistent results. In the Framingham study, euthyroid women in the highest tertiles of TSH level were at an increased risk of Alzheimer's disease as compared to those in the middle tertile (4). However, no association was found in men. Two other studies of community-dwelling men and women aged 65 and older reported no association of
TSH with CF (5-7). Previous reports that evaluated replacement treatment for subclinical hypothyroidism on $\mathrm{CF}$ and mood also yielded inconsistent results with both positive (8-10) and negative findings (11).

Effects of replacement therapy with L-thyroxine $\left(\mathrm{LT}_{4}\right)$ in reversing $\mathrm{CF}$ impairment related to overt hypothyroidism have been previously evaluated in a few, mostly uncontrolled, studies $(9,10,12)$. Among 36 women with mild hypothyroidism, $\mathrm{LT}_{4}$ treatment was associated with neuropsychological improvement (12); another study demonstrated improvement in quality of life and psychological symptoms in 43 hypothyroid subjects after treatment (10). Also, experimental studies suggested $\mathrm{LT}_{4}$ treatment reverses hypothyroidisminduced impairment of hippocampus-dependent cognition, probably by restoring levels of signaling molecules important for these processes (13).

Although these studies suggested that CF impairment might be reversible with hypothyroidism treatment, the long-term effect of thyroid hormone treatment on CF 
and mood is still unknown. The aim of the present study is to examine whether long-term hypothyroidism treatment is associated with $\mathrm{CF}$ and mood impairment in old age. We compared the CF of community-dwelling euthyroid older adults with those who had long-term treated hypothyroidism (up to 83 years).

\section{Material and methods}

\section{Study population}

Participants in this study were members of the Rancho Bernardo Cohort, a southern California community of Caucasian adults established in $1972(n=6339)$. These individuals were initially enrolled in a study of heart disease risk factors as part of the Lipid Research Clinics Prevalence Program. The health of these participants has been followed ever since with periodic clinic visits and yearly mailed questionnaires. The details of the initial study have been previously described (14). Between 1999 and 2003, 1141 participants attended a research visit and 1135 participants had sufficient blood obtained for TSH assays. At the same visit, CF and depressed mood were assessed. A total of 1034 individuals with TSH within the normal range were included in this analysis; 101 participants with TSH above or below the normal range and/or a history of thyroid disease without treatment were excluded. All participants provided written informed consent. The study protocol was approved by the Human Research Protection Program at the University of California, San Diego, La Jolla, CA, USA.

In this analysis, participants were classified into two groups as follows: the treated hypothyroid group included participants with a positive history of physician-diagnosed primary hypothyroidism (due to thyroid surgery or autoimmune disease) who were currently using $\mathrm{LT}_{4}$ replacement monotherapy. The euthyroid group included participants without a history of physician-diagnosed thyroid disease and not using thyroid medication. Participants with a positive history of thyroid disease who were not using thyroid medication were excluded from this analysis $(n=24)$.

\section{Data collection}

Clinical and Iaboratory evaluation Clinical and laboratory data were assessed as previously described (15). Education level, current cigarette smoking, alcohol intake ( $\geq 3$ times/week), and regular physical activity (exercise $\geq 3$ times/week) were self-reported using standard questionnaires. Medication use was validated by a trained nurse who examined pills and prescriptions brought to the clinic for that purpose.

Morning fasting blood samples were collected after a 12-h fast. TSH was measured using high-sensitivity assay (normal range $0.49-4.67 \mathrm{mIU} / \mathrm{l}$ ). Fasting total, high density lipoprotein (HDL), and low density lipoprotein (LDL) cholesterol and triglyceride levels were measured in a Center for Disease Control Certified Lipid Research Clinic Laboratory. Total cholesterol and triglyceride levels were measured by enzymatic techniques using an ABA-200 biochromatic analyser (Abbott Laboratories). HDL was measured after precipitation of the other lipoproteins with heparin and manganese chloride. LDL was estimated using the Friedewald formula. Plasma glucose levels were measured by the glucose oxidase method and serum creatinine by the Jaffe reaction method.

Outcomes CF was assessed by a trained interviewer using three standardized CF tests: modified mini-mental state examination (3MSE; 16, 17), Trail-Making Test part B (Trails B; 18), and verbal fluency (19).

The 3MSE assesses orientation, registration, attention, calculation, language, and recall $(16,17)$. It is considered superior to the older Mini-MSE in identifying probable dementia for all levels of cognitive impairment. 3MSE scores range from 0 to 100 with lower scores indicating poorer performance; a cut point of 78 was used to identify global cognitive impairment (17).

The Trails B from the Halstead-Reitan Neuropsychological Test Battery tests visuomotor tracking and attention (18). The participant scans a page continuously to identify numbers and letters in a specified sequence while shifting from number to letter sets. A maximum of $300 \mathrm{~s}$ is allowed. Performance is rated by the time required to finish the test; higher scores indicate poorer performance. Better performance on Trails B is significantly associated with the ability to perform instrumental activities of daily living in community-dwelling elderly (20).

Category fluency assessed verbal memory by asking the participant to name as many animals as possible in $1 \mathrm{~min}$ (19). The score is the number of animals named correctly, with lower scores indicating poorer performance.

Depressed mood was assessed using the Beck Depression Inventory (BDI) (21), a self-administered questionnaire consisting of 21 sets of items. For each set, participants were asked to choose the statement that best described their feelings. Scores are summed over the 21 items; higher scores indicate greater depressed mood; a score of 13 or higher suggests clinical depression.

\section{Statistical analysis}

In univariate analyses, clinical characteristics were compared by thyroid status using Student $t$-tests and $\chi^{2}$ analysis. Comparisons of adjusted mean scores on CF tests and BDI were examined with analysis of covariance. Covariates were chosen based on their univariate associations with the outcomes, clinical relevance, and the existence of differences between the groups on that variable as well as the results from 
Table 1 Baseline characteristics by thyroid status.

\begin{tabular}{|c|c|c|c|}
\hline & $\begin{array}{l}\text { Treated } \\
\text { hypothyroidism } \\
(n=149)\end{array}$ & $\begin{array}{l}\text { Euthyroid } \\
(n=885)\end{array}$ & $\boldsymbol{P}$ \\
\hline Mean age (years) & $76.1 \pm 9.6$ & $73.6 \pm 10.2$ & 0.005 \\
\hline TSH (mlU/l) & $1.54(1.59)$ & $1.57(1.19)$ & 0.81 \\
\hline $\begin{array}{l}\text { Body mass index } \\
\left(\mathrm{kg} / \mathrm{m}^{2}\right)\end{array}$ & $27.4 \pm 5.5$ & $27.1 \pm 4.3$ & 0.55 \\
\hline $\begin{array}{l}\text { Systolic blood } \\
\text { pressure (mmHg) }\end{array}$ & $141 \pm 19$ & $139 \pm 20$ & 0.11 \\
\hline $\begin{array}{l}\text { Diastolic blood } \\
\text { pressure }(\mathrm{mmHg})\end{array}$ & $77 \pm 10$ & $78 \pm 9$ & 0.16 \\
\hline $\begin{array}{l}\text { Fasting blood glucose } \\
\qquad(\mathrm{mmol} / \mathrm{l})\end{array}$ & $5.17 \pm 0.88$ & $5.33 \pm 1.3$ & 0.06 \\
\hline $\begin{array}{l}\text { Total cholesterol } \\
(\mathrm{mmol} / \mathrm{l})\end{array}$ & $5.46 \pm 1.08$ & $5.23 \pm 0.98$ & 0.009 \\
\hline LDL-c (mmol/l) & $3.00 \pm 0.9$ & $2.92 \pm 1.1$ & 0.56 \\
\hline HDL-c (mmol/li) & $1.65 \pm 0.5$ & $1.52 \pm 0.4$ & 0.009 \\
\hline Triglycerides (mmol/l) & $1.58(1.14)$ & $1.46(1.05)$ & 0.46 \\
\hline Creatinine $(\mu \mathrm{mol} / \mathrm{l})$ & $63.3 \pm 23$ & $67.1 \pm 23$ & 0.15 \\
\hline
\end{tabular}

Mean \pm s.D. or median (interquartile range).

previous studies of CF within this cohort. Initially ageadjusted comparisons were performed followed by multivariable modeling; the first model included age, sex, and antidepressant medication as covariates; the second model included BDI instead of antidepressant medication; the third model included age, sex, antidepressant medication, regular exercise, and total cholesterol.

The calculated power using PASS statistical software (NCSS, Kaysville, UT, USA) to detect a 0.5 S.D. difference in mean CF test scores between groups was $>90 \%$ for each CF test. All analyses were performed using SPSS (version 13.1, SPSS, Inc., Chicago, IL, USA); $P$ values (two-tailed) $<0.05$ were considered significant.

\section{Results}

A total of 1034 participants (mean age $73.9 \pm 10.1$; $41.3 \%$ men) were included; 149 had treated primary hypothyroidism and 885 were euthyroid. The currently treated hypothyroid group had been treated with $\mathrm{LT}_{4}$ for an average of 20 years; mean current $\mathrm{LT}_{4}$ dosage was $1.4 \pm 0.8 \mu \mathrm{g} / \mathrm{kg}$ or $100 \pm 28 \mathrm{mcg}$. TSH levels were similar between groups (euthyroid: 1.57 (1.19) versus treated hypothyroidism: 1.54 (1.59) $\mathrm{mIU} / \mathrm{l}, \mathrm{P}=0.81)$.

Those with treated hypothyroidism were older than the euthyroid group $(76.1 \pm 9.6$ vs $73.6 \pm 10.2$ years, $P=0.005$; Table 1$)$, and more likely to be women (81.6 vs $54.8 \%, P<0.001)$. Compared to euthyroid participants, those in the treated hypothyroidism group reported less regular physical exercise (60.8 vs $71.9 \%$, $P=0.006)$ and higher rates of antidepressant medication use ( 19.5 vs $8.5 \%, P<0.001)$. Education level (some from college onwards), alcohol intake ( $\geq 3$ times/week), and psychotropic medication intake did not differ significantly between groups.

Cognitive impairment (3MSE score $<78$ ) was present in $5.6 \%$ among treated hypothyroidism group versus $5.2 \%$ among euthyroid $(P=0.85)$. BDI, 3MSE, Trails B, and verbal fluency test scores were not significantly different between groups before and after adjusting for age and other covariates (Table 2). The same pattern was observed in sex-stratified analysis. Further adjustments for HDL and fasting blood glucose did not change the results. Also, no differences in $\mathrm{CF}$ were observed when the hypothyroidism group was compared by tertiles of duration of $\mathrm{LT}_{4}$ treatment (tertiles: $<6$ years, 6-27 years, $>27$ years); CF test scores were 3MSE: $91 \pm 1.8$ vs $90 \pm 1.6$ vs $89 \pm 1.7, P$ for trend 0.36 ; Trails B: $120 \pm 9.4$ vs $120 \pm 8.3$ vs $144 \pm 9, P$ for trend

Table 2 Cognitive function tests scores by thyroid status.

\begin{tabular}{|c|c|c|c|}
\hline & $\begin{array}{l}\text { Treated hypothyroidism } \\
\qquad(n=149)\end{array}$ & $\begin{array}{l}\text { Euthyroid } \\
(n=885)\end{array}$ & $\boldsymbol{P}$ \\
\hline Age-adjusted & Means \pm S.E.M. & Means \pm S.E.M. & \\
\hline Beck Depression Inventory score & $5.50 \pm 0.35$ & $4.90 \pm 0.14$ & 0.10 \\
\hline Modified mini-mental state exam & $90.5 \pm 1.05$ & $90.7 \pm 0.44$ & 0.82 \\
\hline Trails B & $122.9 \pm 4.53$ & $115.9 \pm 1.90$ & 0.15 \\
\hline Verbal fluency & $17.8 \pm 0.40$ & $18.1 \pm 0.16$ & 0.37 \\
\hline \multicolumn{4}{|c|}{ Model 1: adjusted for age, sex, antidepressant medication } \\
\hline Beck Depression Inventory score & $5.23 \pm 0.35$ & $5.07 \pm 0.15$ & 0.68 \\
\hline Modified mini-mental state exam & $90.6 \pm 1.10$ & $90.6 \pm 0.50$ & 0.97 \\
\hline Trails B & $120.0 \pm 4.60$ & $117.2 \pm 1.97$ & 0.60 \\
\hline Verbal fluency & $18.0 \pm 0.40$ & $18.0 \pm 0.17$ & 0.99 \\
\hline \multicolumn{4}{|c|}{ Model 2: adjusted for age, sex, Beck Depression Inventory score } \\
\hline Modified mini-mental state exam & $90.5 \pm 1.10$ & $90.8 \pm 0.45$ & 0.79 \\
\hline Trails B & $119.5 \pm 4.7$ & $115.7 \pm 1.90$ & 0.44 \\
\hline Verbal fluency & $18.1 \pm 0.41$ & $18.2 \pm 0.16$ & 0.91 \\
\hline \multicolumn{4}{|c|}{$\begin{array}{l}\text { Model 3: adjusted for age, sex, antidepressant medication, } \\
\text { regular exercise, total cholesterol }\end{array}$} \\
\hline Beck Depression Inventory score & $5.12 \pm 0.35$ & $5.09 \pm 0.15$ & 0.92 \\
\hline Modified mini-mental state exam & $90.8+1.10$ & $90.5+0.48$ & 0.82 \\
\hline Trails B & $118.0 \pm 4.62$ & $117.4 \pm 1.96$ & 0.90 \\
\hline Verbal fluency & $18.1 \pm 0.40$ & $18.0 \pm 0.16$ & 0.78 \\
\hline
\end{tabular}


Table 3 Cognitive function tests scores by thyroid status in analysis with matched age and sex.

\begin{tabular}{|c|c|c|c|}
\hline & $\begin{array}{c}\text { Treated } \\
\text { hypothyroidism } \\
(n=113)\end{array}$ & $\begin{array}{l}\text { Euthyroid } \\
(n=452)\end{array}$ & $P$ \\
\hline $\begin{array}{l}\text { Beck Depression } \\
\text { Inventory score }\end{array}$ & $\begin{array}{r}\text { Means } \pm \text { s.D. } \\
5.4 \pm 4.0\end{array}$ & $\begin{array}{r}\text { Means } \pm \text { s.D. } \\
5.3 \pm 4.4\end{array}$ & 0.91 \\
\hline $\begin{array}{l}\text { Modified mini-mental } \\
\text { state exam }\end{array}$ & $90.2 \pm 13.8$ & $89.6 \pm 13.1$ & 0.64 \\
\hline Trails B & $126.4 \pm 70.9$ & $129.0 \pm 66.1$ & 0.70 \\
\hline Verbal fluency & $17.7 \pm 5.42$ & $17.3 \pm 5.06$ & 0.47 \\
\hline
\end{tabular}

0.06; and verbal fluency: $17 \pm 0.6$ vs $18 \pm 0.6$ vs $17 \pm 0.6, P$ for trend 0.80 for first, second, and third tertiles respectively.

Repeating the analyses but including those with abnormal TSH (below or above the normal range) did not materially change the results. Also, in order to exclude individuals with possible nonthyroidal illness syndrome, further analysis was performed excluding individuals with chronic diseases (e.g. kidney disease, cancer, severe cardiovascular disease); the results did not change.

In further analysis, treated hypothyroidism participants were compared with an age- and sex-matched sample from the control group (1:4) on CF and risk factors after excluding participants taking antidepressant medication $(n=68)$. In this analysis, 452 participants were euthyroid (mean age 77.5 \pm 9.0 years; $77 \%$ women) and 113 had treated hypothyroidism (mean age $77.3 \pm 9.3$ years; $81 \%$ women). Table 3 shows the $\mathrm{CF}$ and $\mathrm{BDI}$ scores among groups. There were no differences in both $\mathrm{CF}$ and BDI scores.

\section{Discussion}

In this large study, long-term treatment of hypothyroidism was not associated with impaired CF or depressed mood in old age. Also, the duration of $\mathrm{LT}_{4}$ replacement therapy was not associated with worse CF performance.

The recommended treatment for primary hypothyroidism is oral $\mathrm{LT}_{4}$ monotherapy in order to restore clinical euthyroidism and maintain normal levels of TSH (22). Triiodothyronine $\left(\mathrm{T}_{3}\right)$ is the most active thyroid hormone, thus monotherapy with $\mathrm{LT}_{4}$ assumes that peripheral conversion of $\mathrm{T}_{4}$ into $\mathrm{T}_{3}$ is able to restore the active hormone in target tissues (23). The physiologic pattern of thyroid hormone action might raise concerns whether long-standing hormone replacement therapy with $\mathrm{T}_{4}$ alone prevents impairment in CF.

The few previous studies examining CF in treated hypothyroid individuals have reported inconsistent results. Osterweil et al. demonstrated an improvement in CF after 5 months of treatment among 54 adults (average age $=68$ years) with hypothyroidism (24). It was concluded that the deleterious effect of hypothyroidism was partly reversible compared with euthyroid controls, but long-term effects of treatment were not assessed (24). A cross-sectional study reported lower levels of neuro $\mathrm{CF}$ and psychological well-being in 141 patients with $\mathrm{T}_{4}$-treated primary hypothyroidism for an average of 5.5 years, compared to a reference population (25). Although this study has an adequate sample for $\mathrm{CF}$ analysis it lacked a control group and assessment for other known CF confounders. Similarly, another community-based study performed in the UK reported that patients on $\mathrm{T}_{4}$ replacement displayed significant impairment in psychological well-being compared to controls of similar age and sex (26). Recently, Samuels et al. reported a decrement in health status, psychological function, working memory, and motor learning in 34 treated hypothyroid subjects compared to 20 euthyroids aged 20-45 years with TSH within the normal range (27).

The present study evaluated an elderly populationbased sample with long-term $\mathrm{LT}_{4}$ treatment, and cannot be compared directly to other previous reports, which examined younger clinical samples for relatively short durations of treatment ( 5 months to 5.5 years). Additionally, the instruments used to assess CF limit comparisons.

Our study has several strengths. To our knowledge, this is the first report assessing the long-term effect of $\mathrm{LT}_{4}$ treatment on CF in the elderly; a control group was available and most known covariates of CF could be taken into account in adjusted analysis. Also, the results were the same in an analysis of groups with similar age and gender prevalence.

This study is limited in that the majority of the Rancho Bernardo Study cohort is middle class with relatively high education levels; cognitive results might not generalize to other populations. This study is also limited in that only one measurement of TSH was available, pre- versus post-treatment data for participants using $\mathrm{T}_{4}$ was not available, and there was no information on the duration of hypothyroidism before treatment was begun. Although $\mathrm{T}_{4}$ hormone measurements were not obtained, TSH measurement is usually sufficient to assess the adequacy of current hypothyroidism treatment (22). A major concern in older individuals is the co-existence of nonthyroidal illness syndrome, which is detected through measurement of $\mathrm{T}_{3}$ and $\mathrm{T}_{4}$ along with TSH. However, results of the present study were not altered after excluding individuals with chronic diseases, thus indicating the relatively small potential effect of the lack of $\mathrm{T}_{3}$ and $\mathrm{T}_{4}$.

The CF tests used in the present study assess different cognitive domains and are well-validated and recognized tools for identifying CF impairment. However, these $\mathrm{CF}$ tests are not without limitations. For instance, none of these tests have higher sensitivity to evaluate small changes in working memory which may be impaired in hypothyroidism (28). Furthermore, the 3MSE and Trails B may not be the most sensitive tests 
to identify minor CF impairment, which may obscure small differences between groups.

In conclusion, long-term treated hypothyroidism with $\mathrm{LT}_{4}$ monotherapy was not associated with impaired CF or depressed mood in old age. These results are reassuring for the cognitive status of older adults after long-term use of $\mathrm{LT}_{4}$ replacement therapy.

\section{Declaration of interest}

The authors declare that there is no conflict of interest that could be perceived as prejudicing the impartiality of the research reported.

\section{Funding}

The Rancho Bernardo Study was funded by the National Institutes of Health/National Institute on Aging grant AG07181 and grant AG028507 and the National Institute of Diabetes and Digestive and Kidney Diseases, grant DK31801. C K Kramer was a recipient of a grant from CAPES (Coordenacao de Aperfeicoamento de Pessoal de Nivel Superior)/Brazil (PDEE (Programa de Doutorada no Pais com Estagio no Exterior) sandwich).

\section{References}

1 Davis JD \& Tremont G. Neuropsychiatric aspects of hypothyroidism and treatment reversibility. Minerva Endocrinologica 200732 $49-65$.

2 Bernal J. Action of thyroid hormone in brain. Journal of Endocrinological Investigation 200225 268-288.

3 Dugbartey AT. Neurocognitive aspects of hypothyroidism. Archives of Internal Medicine 1998158 1413-1418.

4 Tan ZS, Beiser A, Vasan RS, Au R, Auerbach S, Kiel DP, Wolf PA \& Seshadri S. Thyroid function and the risk of Alzheimer disease: the Framingham Study. Archives of Internal Medicine 2008168 1514-1520.

5 Volpato S, Guralnik JM, Fried LP, Remaley AT, Cappola AR \& Launer LJ. Serum thyroxine level and cognitive decline in euthyroid older women. Neurology 200258 1055-1061.

6 Manciet G, Dartigues JF, Decamps A, Barberger-Gateau P, Letenneur L, Latapie MJ \& Latapie JL. The PAQUID, survey and correlates of subclinical hypothyroidism in elderly community residents in the southwest of France. Age and Ageing $1995 \mathbf{2 4}$ 235-241.

7 Roberts LM, Pattison H, Roalfe A, Franklyn J, Wilson S, Hobbs FD \& Parle JV. Is subclinical thyroid dysfunction in the elderly associated with depression or cognitive dysfunction? Annals of Internal Medicine 2006145 573-581.

8 Monzani F, Del Guerra P, Caraccio N, Pruneti CA, Pucci E, Luisi M \& Baschieri L. Subclinical hypothyroidism: neurobehavioral features and beneficial effect of L-thyroxine treatment. Clinical Investigator 199371 367-371.

9 Miller KJ, Parsons TD, Whybrow PC, van Herle K, Rasgon N, van Herle A, Martinez D, Silverman DH \& Bauer M. Memory improvement with treatment of hypothyroidism. International Journal of Neuroscience 2006116 895-906.

10 Gulseren S, Gulseren L, Hekimsoy Z, Cetinay P, Ozen C \& Tokatlioglu B. Depression, anxiety, health-related quality of life, and disability in patients with overt and subclinical thyroid dysfunction. Archives of Medical Research 200637 133-139.

11 Jorde R, Waterloo K, Storhaug H, Nyrnes A, Sundsfjord J \& Jenssen TG. Neuropsychological function and symptoms in subjects with subclinical hypothyroidism and the effect of thyroxine treatment. Journal of Clinical Endocrinology and Metabolism 200691 145-153.
12 Bono G, Fancellu R, Blandini F, Santoro G \& Mauri M. Cognitive and affective status in mild hypothyroidism and interactions with L-thyroxine treatment. Acta Neurologica Scandinavica 2004110 59-66.

13 Alzoubi KH, Gerges NZ, Aleisa AM \& Alkadhi KA. Levothyroxin restores hypothyroidism-induced impairment of hippocampusdependent learning and memory: behavioral, electrophysiological, and molecular studies. Hippocampus 200919 66-78.

14 Barrett-Connor E. The prevalence of diabetes mellitus in an adult community as determined by history or fasting hyperglycemia. American Journal of Epidemiology 1980111 705-712.

15 Kramer CK, von Muhlen D, Gross JL, Laughlin GA \& BarrettConnor E. Blood pressure and fasting plasma glucose rather than metabolic syndrome predict coronary artery calcium progression: the Rancho Bernardo Study. Diabetes Care 200932 141-146.

16 Folstein MF, Folstein SE \& McHugh PR. 'Mini-mental state'. A practical method for grading the cognitive state of patients for the clinician. Journal of Psychiatric Research 197512 189-198.

17 Teng EL \& Chui HC. The modified mini-mental state (3MS) examination. Journal of Clinical Psychiatry 198748 314-318.

18 Reitan R. Validity of the Trail-Making Test as an indicator of organic brain disease. Perceptual and Motor Skills $1958 \mathbf{8}$ 271-276.

19 Borkowski JG, Benton AL \& Spreen O. Word fluency and brain damage. Neuropsychologia 19675 135-140.

20 Cahn-Weiner DA, Boyle PA \& Malloy PF. Tests of executive function predict instrumental activities of daily living in communitydwelling older individuals. Applied Neuropsychology 20029 187-191.

21 Beck AT, Ward CH, Mendelson M, Mock J \& Erbaugh J. An inventory for measuring depression. Archives of General Psychiatry 19614 561-571.

22 Baskin HJ, Cobin RH, Duick DS, Gharib H, Guttler RB, Kaplan MM \& Segal RL. American Association of Clinical Endocrinologists medical guidelines for clinical practice for the evaluation and treatment of hyperthyroidism and hypothyroidism. Endocrine Practice 20028 457-469.

23 Bianco AC, Salvatore D, Gereben B, Berry MJ \& Larsen PR. Biochemistry, cellular and molecular biology, and physiological roles of the iodothyronine selenodeiodinases. Endocrine Reviews 200223 38-89.

24 Osterweil D, Syndulko K, Cohen SN, Pettler-Jennings PD, Hershman JM, Cummings JL, Tourtellotte WW \& Solomon DH. Cognitive function in non-demented older adults with hypothyroidism. Journal of the American Geriatrics Society $1992 \mathbf{4 0}$ 325-335.

25 Wekking EM, Appelhof BC, Fliers E, Schene AH, Huyser J, Tijssen JG \& Wiersinga WM. Cognitive functioning and wellbeing in euthyroid patients on thyroxine replacement therapy for primary hypothyroidism. European Journal of Endocrinology 2005 $153747-753$.

26 Saravanan P, Chau WF, Roberts N, Vedhara K, Greenwood R \& Dayan CM. Psychological well-being in patients on 'adequate' doses of L-thyroxine: results of a large, controlled communitybased questionnaire study. Clinical Endocrinology $2002 \mathbf{5 7}$ $577-585$.

27 Samuels MH, Schuff KG, Carlson NE, Carello P \& Janowsky JS. Health status, psychological symptoms, mood, and cognition in L-thyroxine-treated hypothyroid subjects. Thyroid $2007 \mathbf{1 7}$ 249-258.

28 Zhu DF, Wang ZX, Zhang DR, Pan ZL, He S, Hu XP, Chen XC \& Zhou JN. fMRI revealed neural substrate for reversible working memory dysfunction in subclinical hypothyroidism. Brain 2006 129 2923-2930.

Received 1 September 2009

Accepted 11 September 2009 